\title{
Humanities \\ Centracare: A history of the New Brunswick Provincial Lunatic Asylum
}

Mike Wong MD

Department of Anesthesiology, Pain Management \& Perioperative Medicine, Dalhousie

University, QEIl Health Sciences Centre, Halifax, NS, Canada

The illusionist Harry Houdini visited Saint John in the summer of 1896, and claimed to have been invited to tour the asylum by then - medical superintendent Dr. James Steeves. According to his own apocryphal account, Houdini watched in rupture as a camisole de force (straitjacket) was used to restrain a violent patient, and he was later pleased to be gifted one of these devices by Steeves. The straitjacket would be used as an essential prop in Houdini's popular escape routines. Though this origin story that Houdini frequently told during his magic act was likely entirely fictional, the mysterious and foreboding allure of the asylum did provide a mesmerizing setting to capture the imagination of his audiences. ${ }^{5,13}$

$\mathrm{T}$ he story of the New Brunswick Provincial Lunatic Asylum reflects the evolution of mental health care in the Maritime provinces and in developed countries in general. The origins of the asylum demonstrate a burgeoning awareness of mental health as a priority for the provincial government, and the institution's decline in the latter half of the twentieth century coincides with changing conceptions about the origins of mental illness, as well as its management.

This article summarizes the history of the facility now known as Centracare, beginning with its inauguration as the oldest mental health institution in British North America and following the changes brought on during the deinstitutionalization movement that reshaped mental health services in New Brunswick and beyond.

\section{Early Years in the Provincial Lunatic Asylum}

In early New Brunswick the care of mad persons, along with the unemployed, poor, and other indigents, was first outlined in the Poor Law of 1786.,2 Under this legislation, local parishes were responsible for dealing with their poor. Some jurisdictions operated special work-houses where paupers were confined to hard labour, others attempted to provide housing placements, while others yet traded paupers by public auction or bound their children to apprenticeship. Incarceration was a common fate for the destitute in New Brunswick, as well as those persons considered mad or dangerous. ${ }^{2}$

It was in this context that Dr. George Peters set about reforming New Brunswick's mental health care in the 1830s. Serving as the visiting medical officer of the Saint John county jail, he bore witness to squalid and overcrowded conditions for imprisoned lunatics, who were housed alongside otherwise sane criminals. He was first able to relocate about two dozen of these mentally ill people from the jail to the city almshouse, a structure which also quickly proved too small to treat or comfortably house them. With the help of fellow Saint Johner George Matthews, on November 14,
1835 , Dr. Peters once again moved the lunatics to the basement of a former cholera hospital on Leinster St. in uptown Saint John. This temporary asylum marked the beginning of British North America's first mental institution. ${ }^{3,4}$

Unfortunately, the temporary asylum was immediately filled to overcapacity with the mentally ill. This development, along with general concerns over a rising population of mentally ill inmates in local jails, spurred the 1836 establishment of a provincial commission to plan for a permanent Provincial Lunatic Asylum in the Saint John area. ${ }^{5}$ The commission conducteda thorough investigation into the organization of asylum care in Europe and the eastern United States, and was suitably impressed with the potential for these institutions to cure madness. ${ }^{6}$ Briefly, there were discussions with the governments of Nova Scotia and Prince Edward Island to pool resources toward a single institution to service the Maritime provinces; however, the provinces opted instead to independently build and operate their own facilities. ${ }^{5}$ In the face of an economic downturn in New Brunswick and competing public works projects, funding for constructing a provincial asylum was delayed for almost a decade. ${ }^{3}$

In 1846, the government of New Brunswick finally approved $2500 £$ toward erection of the permanent asylum. The 50-acre site was located in an area called Simms Corner, in the parish of Lancaster, about one mile outside of Saint John city limits. Overlooking the Reversing Falls, and enjoying a view of the harbour and city, this site provided a bucolic setting for housing the insane. ${ }^{5}$ In accordance with mid-nineteenth century views that modernization, industrialization, and mental overstimulation were major causes of madness, isolation to such an idyllic rural locale was deemed ideal for these patients' recovery., Incidentally, the remoteness of the site spared the Provincial Asylum from destruction during the Great Fire of Saint John in 1877, that destroyed over 1400 homes and rendered 6000 residents homeless. $^{5}$

A cornerstone was laid on June 24, 1847, in a jubilant ceremony attended by the Lieutenant Governor, the 
mayor, various municipal and provincial officials, and officers of the local Masonic lodge. Construction then began in earnest. In December 1848, residents of the temporary asylum were finally transferred to the new Provincial Lunatic Asylum, with Dr. Peters briefly serving as the first medical superintendent of the institution (Figure 1). ${ }^{5}$

From the start, there was a desire to provide vocational activities for patients. On the asylum's spacious grounds patients staffed a working farm with vegetable crops and housing for livestock. Likewise, clothing was made by female patients under the direction of a professional seamstress. The labour provided by patients was not only considered therapeutic, but also helped offset the costs associated with operating the asylum. Sadly, it was not long before the dream of a productive and therapeutic asylum farm were impeded by nearby infrastructure projects. First, the asylum grounds were transected by the construction of a suspension bridge across the Reversing Falls in 1853, and this was followed in 1885 by the addition of a nearby railway bridge, effectively reducing the asylum grounds to only four acres. ${ }^{5}$

To continue operating an asylum farm, an additional 210-acre plot of land was purchased over a mile away in 1885; this would become known as the "Annex."5,7 Unfortunately, the remoteness of this site from the main building limited access to all but the most stable and functional of patients, so the Annex farm would never reach its full potential. Later requests to the provincial government to relocate the entire institution to a larger site went unheeded. ${ }^{8}$ Nonetheless, agricultural activities at the Annex farm continued to provide a small source of revenue for the institution until it was phased out by the 1970s. ${ }^{5}$

Aside from providing supervised labour, occasional leisure opportunities, a quiet rural environment, and isolating patients from their friends and family, treatment options for the asylum's mentally ill were fairly limited. Common therapies tended to be physical in nature, and they included: cold water baths, phlebotomy, emetics, laxatives, and injectable sedatives. ${ }^{3,6}$ By 1890 , only about $3 \%$ of asylum patients were expected to be "restored to mental health." With these measures proven time and again to be ineffective, clinicians had little recourse than to suppose that a majority of patients simply were not brought to the asylum early enough in their condition to effect a cure. ${ }^{3}$ Many patients, once admitted, spent the rest of their lives at the institution.

In practice, the asylum became a place to store people who did not fit in with society at large, and it cared for them in mostly a custodial role. This attitude is reflected in contemporaneous provincial legislation concerning disposition of the insane. For example, a 1852 law permitted an insane person to be forcibly admitted to the asylum, on the order of two Justices of the Peace, without requiring a physician's consultation or even the consent of the asylum superintendent. It would not be until 1883 that the asylum's medical superintendent would have the ability to refuse such an admission. ${ }^{3}$ Unsurprisingly, the asylum's population continued to grow over the following decades: it housed an average of 194 patients in $1864,{ }^{9} 394$ patients in $1885,,^{7} 888$ in 1934, ${ }^{10} 1308$ in $1947,{ }^{8}$ and it peaked at 1697 patients in $1956 .{ }^{10}$ As early as the first year after its opening, the medical superintendent had complained about overcrowding at the asylum. ${ }^{3}$ The facility had to be expanded several times over its history, but would always become overcrowded again shortly afterward. ${ }^{11}$ Each subsequent medical superintendent continued to beseech the provincial government, with varying degrees of success, for more funding and resources, competitive wages, and the construction of new facilities. ${ }^{12}$

\section{Modernization in the Provincial Hospital}

The Provincial Lunatic Asylum entered the twentieth century with a rechristening as the Provincial Hospital for Nervous Diseases, in 1903. ${ }^{5}$ Despite this scientificsounding appellation, treatment at the asylum remained much the same as in decades past, and successful patient rehabilitation was hardly any more likely. A sense of resignation is conveyed in the words of Dr. James Anglin, the longest serving medical superintendent of the hospital (1904-1934), and one-time president of the American Psychiatric Association (1917-1918), who wrote:

"...for many persons that are admitted each year, nothing more can be done than to provide shelter - the aged, the paretic, the epileptic, the imbecile. There is no other haven for them in this province." ${ }^{14}$

However, under the administration of Dr. Anglin's successor, Dr. Ernest Menzies, advances in medicine and psychiatry would finally begin to effect change in the hospital. 1936 saw the purchase of an x-ray machine and establishment of a modern operating room, so that surgical conditions could be treated on-site, rather than requiring transfer into another hospital. ${ }^{5}$ Dr. Menzies was also perhaps the first to introduce insulin treatment to a Canadian psychiatric hospital. ${ }^{15}$ An electroshock (electroconvulsive) therapy program was introduced during the Second World War. In 1942, the Provincial Hospital was accredited by the American College of Surgeons. ${ }^{5}$ 


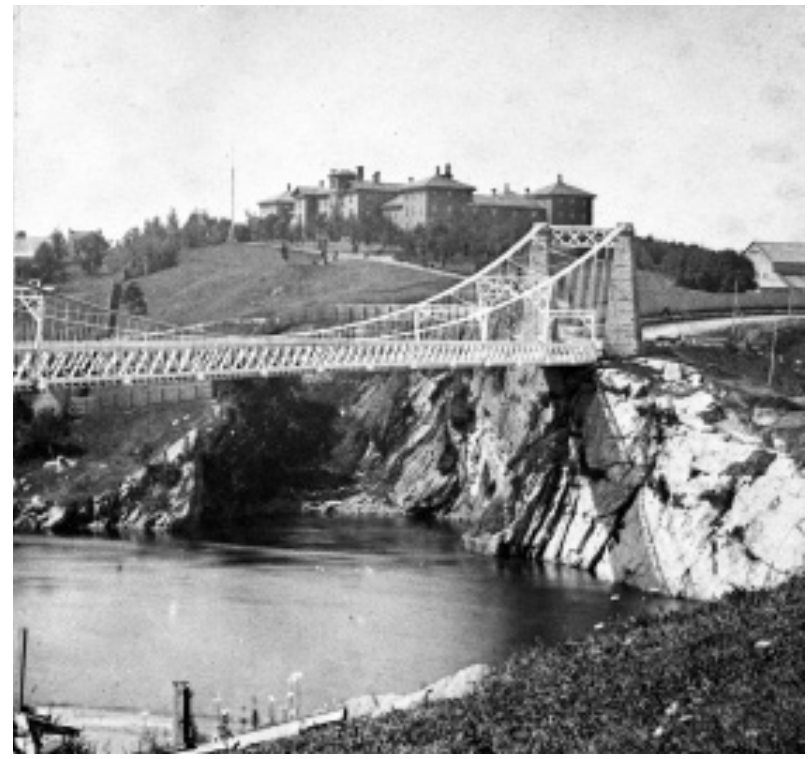

Figure I. The Lunatic Asylum and suspension bridge. Photograph by M. McClure, c. 1870s.

Unfortunately, during the Second World War, many experienced nurses and physicians were deployed in active service, leaving the hospital sparsely staffed. ${ }^{15}$ Increasingly, these poor conditions became subject to very public scrutiny. Over three weeks in January and February 1945, Montreal's The Standard newspaper published an alarming exposé by investigative journalist Kenneth Johnstone, who briefly worked undercover in the hospital as an attendant supervising patients. His article illustrated foul living conditions, patient abuse at the hands of attendants or other patients, liberal use of injectable sedatives without doctors' orders, and a cavalier attitude toward employing physical restraints. ${ }^{11,15}$

These allegations spurred a Royal Commission Inquiry into the veracity of the newspaper's claims. The Baxter Inquiry, as it came to be known, was ultimately sympathetic to the hospital and its workers. It commended the four-member medical staff for continuing the daily administration of the hospital with severely strained and limited resources, and called for medical staff salaries to be raised. However, the inquiry did verify many shortcomings in patients' living conditions, and it recommended renovations to modernize the hospital, as well as development of occupational activities for patients, and creation of a Board of Governors to aid in administration of the hospital. The hospital slowly addressed some of these shortcomings over the next decade. ${ }^{11,15}$

The 1950s continued to bring medical advancements to the Provincial Hospital, including the addition of diagnostic electroencephalography. As in many other institutions, the hospital briefly trialed frontal lobotomy, carrying out 15 of these surgeries

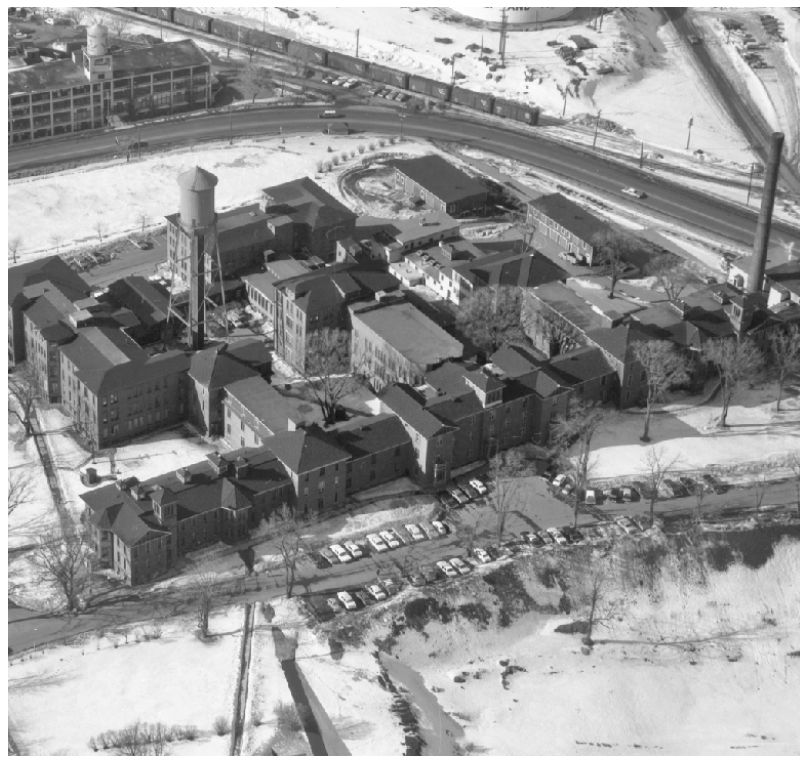

Figure 2. Aerial view, demonstrating later additions to the oldest structures of the Provincial Hospital complex. Photographer unknown. 1965.

in 1953. Once-agitated patients were indeed rendered sedate, but the procedure fell out of favour as these patients unfortunately also became socially disinhibited, and were no better able to navigate interactions with other people. The introduction of chlorpromazine and antipsychotic medications during this decade was far more beneficial. ${ }^{5}$

Outside of the Provincial Hospital, the overall delivery of mental health services in New Brunswick was also starting to change, with the organization of the first outpatient mental health clinics in Saint John, Fredericton, and Moncton around 1950. ${ }^{5}$ Inpatient psychiatric care also began to shift to other institutions. In 1953, 11 psychiatric beds were added to the Moncton Hospital, followed by the 1954 opening of a new 225-bed psychiatric hospital in Campbellton. ${ }^{10}$ The hospital in Campbellton would address long-unmet needs within the Francophone community, since physicians at the Provincial Hospital were historically rarely fluent in French. ${ }^{1} 1956$ saw the largest patient census in the history of the Provincial Hospital but, from this point on, New Brunswick would continue to pursue mental health care decentralization, and the province would join other jurisdictions in moving away from institutionalizing the mentally ill or developmentally delayed..$^{10}$

\section{Centracare, and Process of Deinstitutionalization}

With the provincial government balking at the high cost of running the psychiatric hospitals in Saint John and Campbellton, the 1970s heralded an acceleration in the process of deinstitutionalization. ${ }^{16}$ During these years, foster homes and nursing homes increasingly 
took more of the hospital's stable chronic patients into the community, while psychiatric services were improved at general hospitals throughout the province. ${ }^{1}$ Despite ongoing requests from Provincial Hospital administrators for a brand new facility to replace the century-old complex, the provincial government did not act to do so (Figure 2). ${ }^{17}$

In 1978, the Provincial Hospital underwent a name change to Centracare, and thus came the introduction of a community board of directors to oversee hospital operations. ${ }^{5}$ By the time of the renaming, the patient census at the institution had fallen below 500, and this continued to drop to around 300 over the next decade. ${ }^{18}$ In 1979, the province embarked on the Southern New Brunswick Mental Health Planning Study, recognizing that further major changes to Centracare would result in widespread effects on the remainder of the mental health care system in the province. ${ }^{14}$

The study characterized chronic challenges at Centracare, including high rates of professional turnover, inadequate physical facilities, and poor communication with outpatient services. Additionally, the Planning Committee criticized a lack of active treatment for long-term patients and inadequate programmes for rehabilitation. Some patient groups admitted to Centracare (i.e., the "mentally retarded, psychogeriatric, drug abusers") had specific needs different from that of the general psychiatric patient population, and would likely benefit from separate treatment designed to meet their specific needs. Finally, contrary to the views of the asylum founders, the study concluded that acute and emergency psychiatric treatment would be better addressed in patients' home communities when possible, in order to avoiding disrupting patients' family ties. ${ }^{19,20}$

In 1988, the Frank McKenna government decisively halted preliminary planning for a new 250-bed psychiatric facility in the province, while it focused on the ongoing transfer of mental health care from institutional to community services. ${ }^{21}$ To oversee this transition, the Mental Health Commission of New Brunswick was also formed in 1988. Comprising mental health professionals along with patients and families, the Mental Health Commission was organized into regional boards that oversaw delivery of mental health services, which in turn reported to a provincial board that ensured compliance with provincial policy. ${ }^{22}$ As never before, consumers of mental health services in New Brunswick were increasingly seen as partners in determining the scope of their own care, and this they did enthusiastically. ${ }^{11}$ Though the New Brunswick model garnered praise from observers of Canadian mental health policy for organizing a relatively smooth transition to community-based care, the Mental Health Commission was later disbanded in 1996 for budgetary reasons, and mental health was reintegrated into the provincial Department of Health and Community Services. ${ }^{11,21-23}$

The patient census at Centracare continued to decline so that by 1995 , the facility housed only 125 patients. $^{5}$ As expected, the progressive closure of Centracare as a long-term institutional care facility was associated with a commensurate increase in need for group homes, shelters, and soup kitchens, and these community services initially struggled to keep up with demand. ${ }^{24,25}$ February 23, 1998 saw the opening of a new, smaller facility in the community of South Bay to replace the original hospital. ${ }^{26}$ Since then, Centracare has served as a 50-bed facility for longer term mental health services, specifically serving elderly patients, patients with concomitant developmental delay and a mental health disorder, and patients requiring intensive psychosocial rehabilitation. In contrast to the frenetic activity seen in decades gone by, the new Centracare no longer treats acutely unwell patients, and from 2016 to 2017 there were only 3 admissions. ${ }^{27}$

For two years following the 1998 relocation, the future of the old provincial hospital remained uncertain as the building lay vacant. Having been iteratively expanded in a piecemeal fashion over more than a century, the building had a jarring, disorienting appearance, inspiring this description:

"Today [in the 1990s], when you walk through the building there is a feeling that it doesn't quite fit together. You can see how various administrations tacked on new wings and rooms as the buildings filled to bursting with people. There are beautiful multi-panel windows set in wood looking out over a stairwell that seems to lead nowhere. There are rooms that can only be entered from a hallway one floor below. And there are walls that don't seem to serve a purpose." ${ }^{10}$

Nonetheless, the Saint John Preservation Review Board and local history enthusiasts advocated for preservation of the facility, citing the value of the institution to the city's history, as well as the impressive Italianate architecture of the original buildings. ${ }^{28}$ The fate of the former asylum was decided November 21, 1998 , after the province accepted a $\$ 1$-million bid from J.D. Irving Ltd. to purchase the site and convert it into a park. ${ }^{29}$ The complex was demolished the next year. ${ }^{30}$

\section{References}

1. St-Amand N. The politics of madness. Halifax, NS: Formac; 1985.

2. Whalen JM. Social welfare in New Brunswick, 1784-1900. Acadiensis. 1972;2(1):54-64.

3. Francis D. That prison on the hill: The historical origins of the lunatic asylum in the Maritime provinces. [Ottawa, ON]; 1975.

4. Francis D. The development of the lunatic asylum in the Maritime provinces. Acadiensis. 1977;6(2):23-38. 
5. Goss D. 150 years of caring: The continuing history of Canada's oldest mental health facility. Saint John, NB: MindCare New Brunswick; 1998.

6. Simonds C, Street WH, Robertson J, Paddock T, Coster F. Commission on a Provincial Lunatic Asylum. 1836.

7. Steeves JT. Report of the medical superintendent of the Provincial Lunatic Asylum at Saint John, N.B., for the year 1885. 1885.

8. Menzies EC. Report of the superintendent of the Provincial Hospital, Saint John, N.B., for the year ending Oct. 31st, 1947. 1948.

9. Steeves JT. Report of the medical superintendent of the Provincial Lunatic Asylum at Saint John, N.B., for the year 1864. 1865.

10. deKluyver C. Known to God they rest in his care. TelegraphJournal. 1998 Feb 21.

11. LeBlanc E, St-Amand N. Dare to imagine: From lunatics to citizens. Moncton, NB: Our Voice; 2008.

12. Gregory RA. Report of the superintendent of the Provincial Hospital, Lancaster, N.B., for the period April 1st, 1962 - March 31st, 1963. 1963.

13. Iype M. Feat recalls Houdini's straitjacket tale. TelegraphJournal. 2011 Aug 17.

14. Southern New Brunswick Mental Health Planning Study. Report of the southern New Brunswick Mental Health Planning Committee. 1982.

15. Province of New Brunswick. Report of the Royal Commission Inquiry: The Provincial Hospital. 1945.

16. Morrisey B. Institutionalized care for adults with significant disabilities and mental illnesses in the province of New Brunswick. [Fredericton, NB]; 2015.
17. Anonymous. The Provincial Hospital should go. TelegraphJournal. 1975 Jul 19.

18. Centracare. 1987 Annual Report. 1988.

19. Southern New Brunswick Mental Health Planning Study. Cooperative efforts in mental health planning in southern New Brunswick: Technical report \#2. 1980.

20. Southern New Brunswick Mental Health Planning Study. Mental health needs in regions 1, 2, and 3: Report on a key informant study: Technical report \#4. 1981.

21. Simmie S. If New Brunswick can do it, why can't we? Toronto Star. 1998 Oct 11.

22. Goering P, Wasylenki D, Macnaughton E. Planning mental health services: Current Canadian initiatives. New Directions for Mental Health Services. 1994.

23. Allen G. Expert praises province's mental health system. Telegraph-Journal. 1998 Nov 21.

24. Anonymous. 3 group homes in Saint John to close. CBC News New Brunswick. 2011.

25. Taylor M. Shelter marks 20 years. The Daily Gleaner. 2003 Dec

26. Anonymous. It's moving day for Centracare. Telegraph-Journal. 1998 Feb 24.

27. Horizon Health Network. 2016-2017 Annual Report. 2017.

28. Goguen G. Centracare buildings may be demolished. 1998 Jul 11.

29. Meagher D. Irving buys Centracare [sic]: Purchase details released. The Daily Gleaner. 1998 Dec 2.

30. Kerr G. Demolition of 150-year-old Saint John landmark begins. Telegraph-Journal. 1999 Mar 10.

\section{ANY FINANCIAL INSTITUTION WILL LEND YOU MONEY}
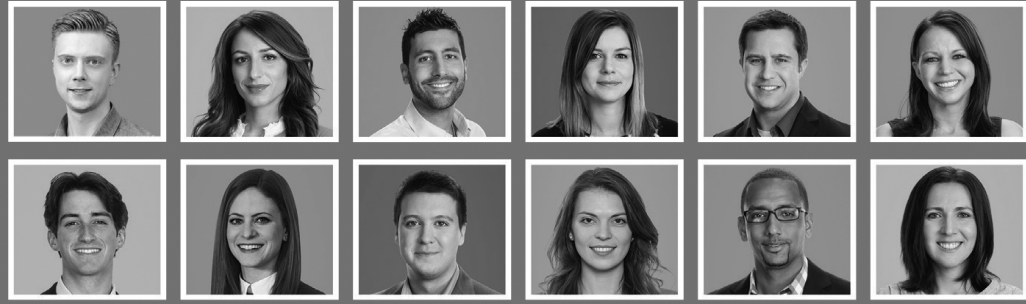

\section{MedEdCounsel}

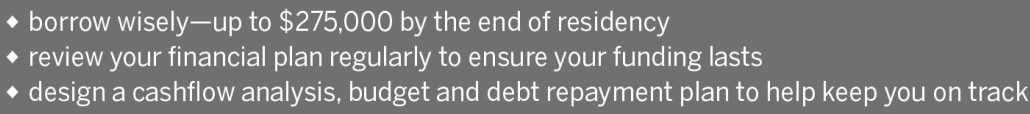

- design a cashflow analysis, budget and debt repayment plan to help keep you on track

LEARN MORE AT MD.CMA.CA/MINIMIZEDEBT OR CALL 1888 855-2555. 